\title{
BASILICA to prevent coronary obstruction in transcatheter aortic valve replacement
}

\author{
J. James Edelman ${ }^{1}$, Jaffar M. Khan $^{2}$ \\ ${ }^{1}$ Department of Cardiothoracic Surgery and Transplantation, Fiona Stanley Hospital and University of Western Australia, Perth, Western Australia, \\ Australia; ${ }^{2}$ Cardiovascular Branch, Division of Intramural Research, National Heart Lung and Blood Institute, National Institutes of Health, \\ Bethesda, Maryland, USA \\ Correspondence to: J. James Edelman, PhD, FRACS. Department of Cardiothoracic Surgery and Transplantation, Fiona Stanley Hospital, Robin \\ Warren Parade, Murdoch 6150, Western Australia, Australia. Email: James.Edelman@health.wa.gov.au.
}

Submitted Mar 05, 2020. Accepted for publication Apr 24, 2020.

doi: $10.21037 /$ acs-2020-av-22

View this article at: http://dx.doi.org/10.21037/acs-2020-av-22

Transcatheter aortic valve replacement (TAVR) has become the treatment of choice in the management of deteriorating, previously implanted surgical aortic valve replacement (SAVR) bioprostheses. TAVR valve-in-valve (ViV) can be performed safely, with lower morbidity and mortality at 30 days compared with redo-SAVR (1).

Coronary obstruction is a rare, but devastating complication of TAVR-ViV. Most often, the site of the obstruction is the coronary ostium, blocked by the old bioprosthesis leaflet as it is stented open by the newly implanted TAVR. A deficient sinus can be predicted by calculating the virtual transcatheter valve-to-coronary distance (VTC) on multidetector computed tomography (MDCT). Similarly, sinus sequestration, where the tip of the bioprosthesis leaflet is stented against a low sinotubular junction (STJ), causes obstruction of the whole sinus. BASILICA is a procedure developed by the National Institutes of Health (NIH) that uses electrocautery to divide the old bioprosthetic (or native valve) leaflet to prevent coronary obstruction (2). The procedure, including preoperative planning, equipment and technique is described in detail in a review by the NIH group (3).

Side-projection and en face views of the coronary arteries are predetermined by reformatting the MDCT. Solo BASILICA can be performed via a single-bore arterial access, allowing accommodation of the two arterial catheters required for the procedure. The aortic valve is crossed and exchanged for a snare catheter. The snare is opened and placed at the left ventricular outflow tract (LVOT), just below the valve. Using the side-projection, a guide catheter (typically
AL2) is placed at the base of the leaflet pointing towards the snare in the LVOT. A coaxial system, consisting of a stiff conductive guidewire (such as the Astato XS-20, Asahi Intecc, Tustin, CA, USA) within an insulating piggyback catheter is positioned at the end of the guide catheter. The end of the Astato wire has its insulation removed using a scalpel, and is attached to a diathermy pencil by hemostat, with the power set at $50 \mathrm{~W}$. Applying electrocautery power, the wire is advanced through the leaflet. Without power, the wire is further advanced about $20 \mathrm{~mm}$ beyond the snare and then snared into the snare-guide.

The piggyback is removed to expose the most proximal part of the exterior $5-7 \mathrm{~cm}$ of the Astato wire. The piggyback is then locked against the wire with a $0.014 "$ torquer and another 0.035 " torquer placed over it. The insulation is removed from the Astato wire for a width of approximately $1 \mathrm{~mm}$ and for approximately 120 degrees of the wire's circumference. A "kink" of at least 90 degrees is then made in the wire using the back of the scalpel blade, ensuring the denuded wire is at the inner part of the kinked "V". Next, by pulling the wire from the LVOT side, the "V" is advanced to the leaflet.

A pigtail catheter is placed at the left ventricular apex to later be used for TAVR. Two $60 \mathrm{~mL}$ syringes filled with dextrose are loaded to the side-arms of the BASILICA catheters. The "slack" is decreased on the system by gently pulling the catheters. Simultaneously, the electrocautery energy is applied, whilst injecting dextrose and pulling the catheters. Haemodynamics typically remain stable after laceration of the leaflet. 
The BASILICA trial recruited thirty patients thought to be at high-risk of coronary obstruction for TAVR (4). BASILICA was successful in $95 \%$. There was $100 \%$ freedom from coronary obstruction and reintervention. There was one death and one disabling stroke at thirty days.

\section{Acknowledgments}

Funding: None.

\section{Footnote}

Conflicts of Interest: JMK is a co-inventor on patents assigned to the National Institutes of Health for purpose-built devices intended to lacerate valve leaflets. The other author has no conflicts of interest to declare.

Open Access Statement: This is an Open Access article distributed in accordance with the Creative Commons Attribution-NonCommercial-NoDerivs 4.0 International License (CC BY-NC-ND 4.0), which permits the noncommercial replication and distribution of the article with the strict proviso that no changes or edits are made and the original work is properly cited (including links to both the

Cite this article as: Edelman JJ, Khan JM. BASILICA to prevent coronary obstruction in transcatheter aortic valve replacement. Ann Cardiothorac Surg 2020;9(6):508-509. doi: 10.21037/acs-2020-av-22 formal publication through the relevant DOI and the license). See: https://creativecommons.org/licenses/by-nc-nd/4.0/.

\section{References}

1. Tam DY, Dharma C, Rocha RV, et al. Transcatheter ViV Versus Redo Surgical AVR for the Management of Failed Biological Prosthesis: Early and Late Outcomes in a Propensity-Matched Cohort. JACC Cardiovasc Interv 2020;13:765-74.

2. Khan JM, Dvir D, Greenbaum AB, et al. Transcatheter Laceration of Aortic Leaflets to Prevent Coronary Obstruction During Transcatheter Aortic Valve Replacement: Concept to First-in-Human. JACC Cardiovasc Interv 2018;11:677-89.

3. Lederman RJ, Babaliaros VC, Rogers T, et al. Preventing Coronary Obstruction During Transcatheter Aortic Valve Replacement: From Computed Tomography to BASILICA. JACC Cardiovasc Interv 2019;12:1197-216.

4. Khan JM, Greenbaum AB, Babaliaros VC, et al. The BASILICA Trial: Prospective Multicenter Investigation of Intentional Leaflet Laceration to Prevent TAVR Coronary Obstruction. JACC Cardiovasc Interv 2019;12:1240-52. 